\title{
A Comparative Study of Heat Transfer between Rotating Circular Smooth-Walled and Square Rib-Roughened Ducts with Cooling Application for Gas Turbine Rotor Blades*
}

\author{
Shyy Woei CHANG** and W. David MORRIS***
}

\begin{abstract}
In this paper we describe a detailed experimental investigation of turbulent heat transfer in radially rotating circular smooth-walled and square rib-roughened ducts with focuses on the variable rotational effects along the leading and trailing surfaces of these two test ducts due to differences in the shape of the cross section and the surface conditions of duct walls. The experimental data reconfirmed the presence of strong rotation-induced secondary flows for both the test sections with an attendant relative increase in local heat transfer on the trailing surface. On the leading surfaces of both test sections, heat transfer was significantly less than that of the pure forced convection level. In qualitative terms, even with the agitated flow field caused by ribs inside the square ribbed duct, considerable rotational effects within the ribbed duct occurred in a similar manner to that found inside the circular smooth-walled duct. However, with equivalent rotating conditions, the heat transfer impediment on the leading surface was more severe for the ribbed duct than for the smooth-walled duct and the heat transfer enhancement on the trailing surface of the ribbed duct was significantly alleviated. A low degree of peripheral heat transfer variation was found in the ribbed test duct. Since the difference between smooth-walled or rib-roughened ducts is considerable, the selection of either circular smooth-walled or square ribroughened coolant channel for gas turbine rotor blades must be performed after considering the variable rotational effects in order to achieve the optimum design of an internal cooling system.
\end{abstract}

Key Words: Orthogonal-Mode Rotating Flow, Turbine Blade Cooling

\section{Introduction}

The working environments encountered in the turbine section of a gas turbine engine raise severe threats to the integrity of turbine components. These threats include extremely high operating temperature, centrifugal and fluctuating mechanical loads, oxidation and damages caused by chemical reactions. Therefore, mechanical stresses along with thermal stress, thermal fatigue, accelerated creep, erosion and

* Receiued 6th May, 1997

** Department of Marine Engineering, National Kaohsiung Institute of Marine Technology, Kaohsiung, Taiwan, R. O. C.

*** Department of Mechanical Engineering, University of Wales, Swansea, Singleton Park, Swansea, SA 2 8 PP, U. K. chemical deterioration significantly constrain the life span of turbine components. However, driven by the scarcity of fossil fuel, the trend toward increaseing turbine entry temperature, TET, in order to improve the power-to-weight ratio and the thermal efficiency of the engine continues. Within a modern gas turbine engine, it is common for the TET to be well above the melting point of the blade material. To cope with this thermodynamic goal, the adoption of conveniently available air as the coolant, bled from a compressor, has become the universal approach to cool down turbine stator and rotor blades. Figure 1 illustrates a typical cooling scheme and the geometry for highpressure turbine blades. An shown, pressurized air bled from certain stages of the compressor is channeled into the nozzle vane and the rotating blades. Inside the rotor blade, the radially inward and 
outward internal coolant channels from a maze-like cooling system in which the coolant is guided and rotated with blade. One of the primary tasks for the employment of a cooling system inside the turbine rotor blade is to reduce the material temperature level and its gradient. Thus the inner surfaces of the internal cooling passages can be either smooth or roughened by various types of ribs. In general, the regions with high external heat flux transferred from the gas side require special treatments for heat transfer augmentation within the internal coolant channels. For this class of heat transfer augmentation, the transverse ribs attached on the inner surface of the coolant channel are of typical fundamental geometry. However, due to the various surface geometries used for the internal coolant channels, the flow fields are modified by the surface enhancement devices under a rotating environment and consequently, various

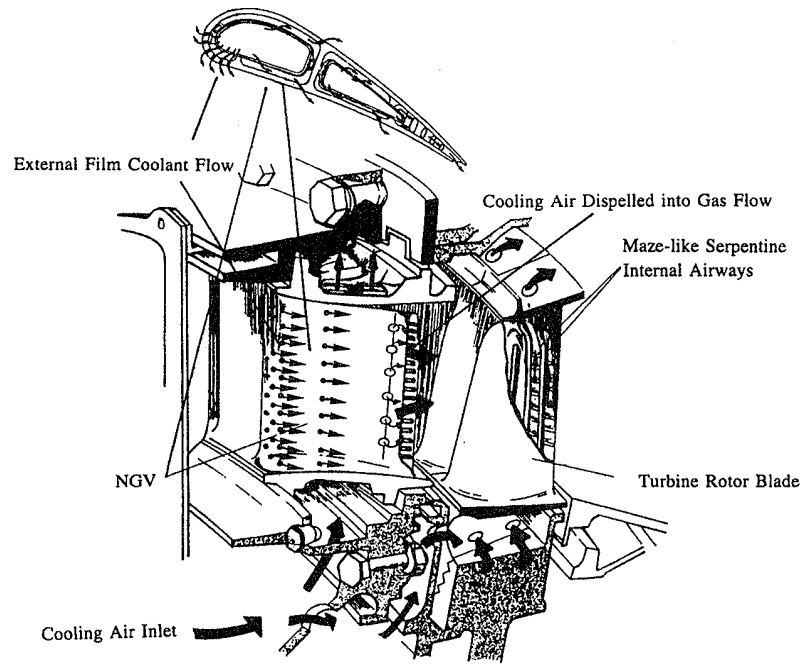

Fig. 1 Typical cooling scheme of gas turbine blades degrees of rotational effects on heat transfer between the smooth-walled and ribbed channels may result.

When the coolant travels in these radially rotating ducts which can be either smooth-walled or ribroughened, both Coriolis and centrifugal forces arise simultaneously due to rotation. The basic flow configuration under the influences of Coriolis and centrifugal forces as shown in Fig. 2 involves a pair of Coriolis secondary flows established on the plane perpendicular to the main-stream. The net results of Coriolis forces are the generation of a double spiral flow and the shift of axial velocity profile toward the trailing edge when the mainstream flows outward ${ }^{(1)}$. On the ribbed wall, the flow that re-circulates after each rib is induced by the ribs themselves even with the presence of rotational forces ${ }^{(2)}$. Near the reattachment point, a locally axial heat transfer peak takes place. If this rotating duct is heated, the density changes of fluid due to temperature variations interfere with the hydrostatic nature of centripetal field and this type of buoyant interaction motivates warmer fluid to move towards the center of rotation. A full background for the heat transfer inside a radially rotating duct with smooth or ribbed wall can be found in "Refs. (1), ( 3 )-(13)". (Morris ${ }^{(1)}$, Mori et al. ${ }^{(3)}$, Morris and Ayhan ${ }^{(4)}$, Medwell et al. ${ }^{(5)}$, Morris and Salemi ${ }^{(6)}$, Chang ${ }^{(7)}$, Han and Zhang ${ }^{(8)}$, Han et al. ${ }^{(9)}$, Johnson et al. ${ }^{(10)}$, Wagner et al. ${ }^{(11)}$, Taslim et al. ${ }^{(12)}$, Taslim et al. $\left.{ }^{(13)}\right)$ However, it has been shown that, for both smooth and rib-roughened duct flows, the convective inertial, Coriolis and centripetal buoyancy forces are coupled to provide significant heat transfer modifications from the equivalent non-rotational situation. With attempts to identify the variable effects of rotation on heat transfer due to different duct wall

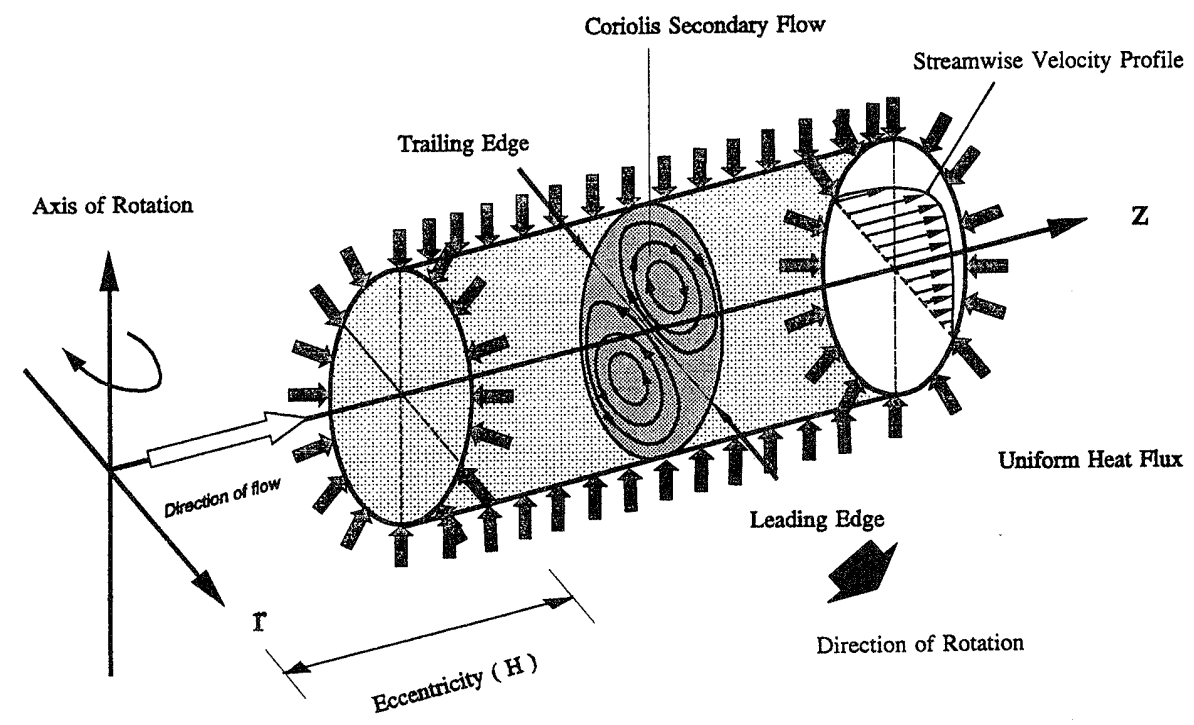

Fig. 2 Fundamental flow geometry of orthogonal-mode rotating heated flow 
geometry, heat transfer experiments within the circular smooth-walled and square ribbed ducts have been performed. In this paper we compare the experimental data generated from the smooth-walled round duct and a square-sectioned duct fitted with transverse ribs, which are both the typical cooling geometry for a gas turbine rotor blade.

\section{Nomenclature}

$a_{e}:$ Smooth entry length of ribbed test duct

$B u$ : Buoyancy number

$C_{p}$ : Specific heat of fluid

$d$ : Hydraulic diameter of test duct

$e$ : Rib height

$H$ : Height of square ribbed duct

$k$ : Thermal conductivity of fluid

$L$ : Active heating length of test duct

$l$ : Rib land

$N u$ : Rotational Nusselt number

$N u_{0}$ : Stationary Nusselt number

$N u_{\infty}$ : Nusselt number value for stationary developed turbulent duct flow

$n$ : Exponent

$P:$ Rib pitch

Pr : Prandtl number

$q$ : Convective heat flux

$R e$ : Reynolds number

Ro: Rossby number

$T_{f}$ : Fluid bulk temperature

$T_{w}$ : Wall temperature of test duct

$W:$ Width of square ribbed duct
$W_{m}$ : Mean through flow velocity

$z$ : Axial location

$Z$ : Dimensionless axial location

$\beta$ : Thermal expansion coefficient of fluid

$\Omega$ : Angular velocity of rotating duct

$\rho$ : Fluid density

$\mu$ : Fluid dynamic viscosity

$\varepsilon$ : Dimensionless eccentricity

$\Psi$ : Unknown function

Subscripts

$L$ : Leading surface of rotating duct

$T$ : Trailing surface of rotating duct

\section{Apparatus}

\subsection{Rotating test facility}

The schematic layout of the rotating test facility is shown in Fig. 3. A hollow air delivery plenum chamber (1) that contained the heat transfer test module (2) was belted to a shaft (3). The heat transfer test module ( 2 ) was fitted with an eccentricity of $150 \mathrm{~mm}$ from the center of rotation. The shaft (3) was supported between two bearings (4). The shaft unit was driven by a DC controllable electrical motor ( 5 ) via a toothed belt-driven pulley system (6). As shown in this figure, pressurized dry and oil free air could flow into rotating plenum chamber (1) from the laboratory supply through the air passage inside the shaft. After the coolant had passed through the test module ( 2 ), heated air was vented into the atmosphere through a convergent-type nozzle (7). This arrangement pressurized the whole flow system,

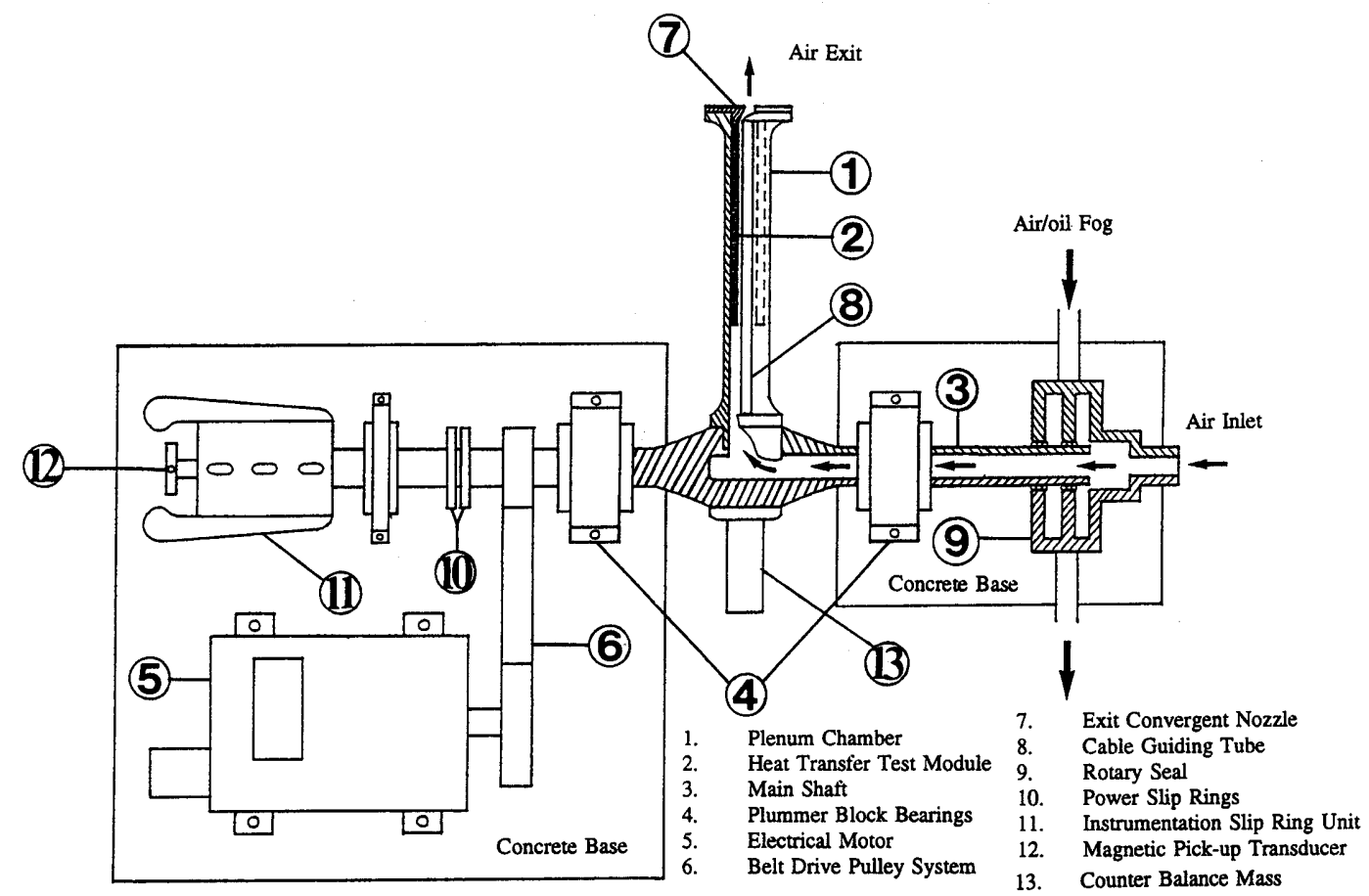

Fig. 3 Schematic layout of rotating test facility 
and which increased the fluid density. Thus, the mean through-flow velocity could be reduced at a given mass flow rate. For a fixed Reynolds number at any rotational speed tested, the reduction of mean throughflow velocity could increase the relative strengths of rotational forces. Therefore, the high-pressure tests enabled real engine simulations at a rotational speed of about $2000 \mathrm{rev} / \mathrm{min}$ for this particular test geometry.

A pair of guiding tubes (8) was connected between the convergent nozzle plate (7) and the rotating shaft through which the electrical heating cables and thermocouple wires were passed. The power slip ring (10) and the instrumentation slip ring (11) were linked with the electrical cables from the guiding tubes ( 8 ) which respectively provided the heating power and transferred the thermocouple signals. Prior to the power slip ring (10), a Variac transformer, an ammeter and a voltmeter were used to control and measure the heating power supply. A Schlumberger SI 3535 D data logger collected all the analog signals from the instrumentation slip ring (11). These signals were then sent to a Dell system 210 PC in which a data acquisition program was loaded to monitor the temperature variations and the flow conditions. Due to the variations in fluid properties as a result of heat transfer, the Reynolds number or other non-dimensional flow parameters were controlled at the preset value within a variation of $\pm 1 \%$ by adjusting the coolant mass flow rate to compensate property changes of fluid. The mass flow rate measurement and the control of the cooling air flow rate were achieved via the use of an orifice-type flow meter and a throttle valve, respectively.

To measure the rotational speed of the shaft, a magnetic transducer (12) picked up the electrical onoff signals from the iron inserts within a tufnol made rotating disc. These frequency signals were then sent to a frequency timer counter to indicate the rotational speed of the shaft in terms of $\mathrm{rev} / \mathrm{min}$.

\subsection{Heat transfer test modules}

The details of the circular smooth-walled and square ribbed test ducts are shown in Fig. 4(a) and 4 ( b ) respectively. In Fig. 4 ( a ), the heated circularsectioned stainless tube, having a thermal conductivity of $15 \mathrm{~W} / \mathrm{mK}$ at $20^{\circ} \mathrm{C}$, was nominally $253 \mathrm{~mm}$ in length and had a bore diameter of $15 \mathrm{~mm}$ with $1.5 \mathrm{~mm}$ wall thickness. It was fitted between the inlet and outlet insulated bushes (2) and ( 3 ), respectively, to give an actively heating length of $225 \mathrm{~mm}$ measured between the inner faces of these two bushes. $\mathrm{A} \mathrm{Ni} / \mathrm{Cr}$ alloy resistance wire, which was spirally wound with $2 \mathrm{~mm}$ pitch on the outer surface of the test tube, provided a basically uniform flux heating resource.
The support bushes and the heated tube were enclosed in an aluminum support tube (4) fitted with external silicon "O" ring seals $(5)$ at both ends.

As shown in Fig. 4( b ) for the square ribbed test duct, five square transverse ribs were fitted at regular downstream intervals. The ribs on leading and trailing surfaces were arranged in an opposite manner. Prior to the first rib, a smooth-walled entry length of $25.5 \mathrm{~mm}$ was used. The geometric specifications of this test duct were described in terms of five nondimensional groups defined in Fig. 4( b) as

Smooth entry length/hydraulic diameter ratio $\left(a_{e}\right)$ d) $=2.83$

Rib height/hydraulic diameter ratio $(e / d)=0.11$

Rib pitch/rib height ratio $(P / e)=10.0$

Land/rib pitch ratio $(l / P)=0.1$

Aspect ratio $(H / W)=1.0$

Basically the contructional details for the squaresectioned ribbed duct were similar to those for the smooth-walled circular duct as shown in Fig. 4(a). The heated square test section ( 1$)$, made of $2-\mathrm{mm}^{-}$ thick stainless steel plates, was held between the insulated bushes (2), (3) and (4). The inner width of this square duct was $9 \mathrm{~mm}$. The rib pitch was 10 $\mathrm{mm}$ and each of the five ribs, machined onto the inner face of duct wall, had a land of $1 \mathrm{~mm}$. A smooth heated wall nominally $25.5 \mathrm{~mm}$ long preceded the first rib and a smooth-walled heating length of $35.5 \mathrm{~mm}$ was incorporated downstream of the final rib. The coolant passages inside both inlet bushes (2), (3) and entry cap (5) were carefully milled into the square section in order to avoid the upstream effects on the test section due to the change of duct geometry. The whole test assembly was enclosed in an aluminum tube (6) fitted with silicon "O" ring seals. The eccentricity measured at the cross-sectional plane where heating commenced was $295 \mathrm{~mm}$. The total heating length of $110 \mathrm{~mm}$ was heated by four Minco thermal-foil heaters $(7)$ with maximum power density of $3.875 \mathrm{~W} / \mathrm{cm}^{2}$ at $125^{\circ} \mathrm{C}$. To fix these heating foils on to the test duct, several layers of tufnol plates (8) were placed on the top of each heating foil and assembled by bolts. Silicone RTV form-type thermal insulation (9) was filled between the encapsulating sheath and the test section in order to minimize heat loss. Similar to the circular test section, a convergenttype nozzle was fitted at the flow exit so that high pressure tests could be performed.

When the circular smooth-walled or square ribbed heat transfer modules were installed into the hollow plenum chamber shown in Fig. 3, sharp flow entry conditions for both the test sections were created. As a result, the hydraulic boundary layers were re-developed from the sharp flow entrances. This 

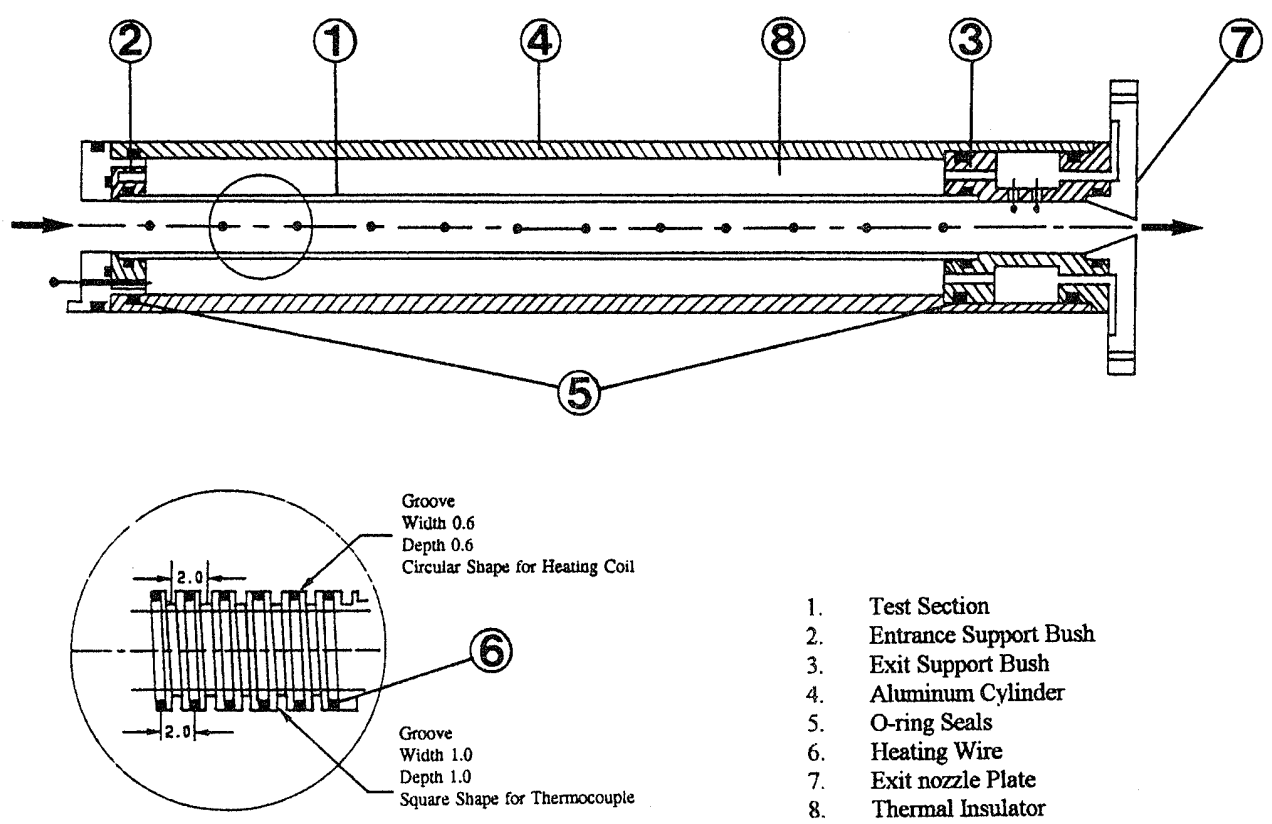

Test Section

Entrance Support Bush

Exit Support Bush

Aluminum Cylinder

O-ring Seals

Heating Wire

Exit nozzle Plate

Thermal Insulator

(a) Circular-sectioned smooth-walled test tube

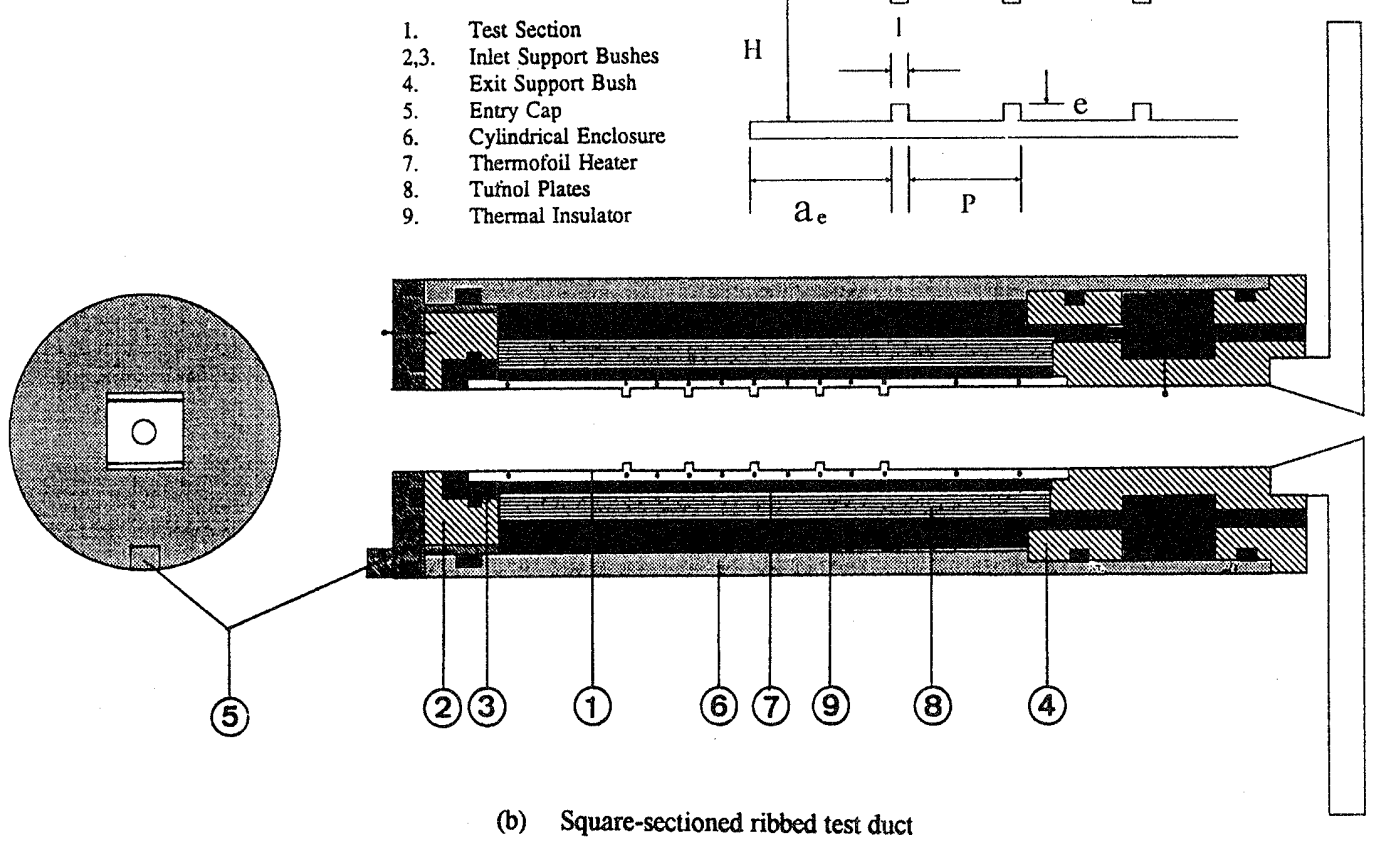

Fig. 4 Heat transfer test modules

geometrical feature simulated the typical flow entry condition for an internal cooling passage of turbine rotor blade. Abrupt entry area ratios from the air plenum to each of the $15-\mathrm{mm}$-diameter circular test tube and $9 \mathrm{~mm}$ square test duct were $7: 1$ and $15: 1$, respectively. For both test sections, the commencement of heating elements was fairly close to the sharp flow entrances as illustrated in Figs. 4( a ) and 4(b). Thus the simultaneous developments of thermal and hydraulic boundary layers with fairly uniform inlet velocity fields at the flow entrances were simulated.

As shown in Figs. 4( a ) and 4(b), twelve type-K thermocouples were mounted on the two axial edges of each heated duct which corresponded to the leading and trailing sufaces when rotating. The thermocouples were actually embedded in the duct wall so that the sensing junctions were $0.5 \mathrm{~mm}$ from the inner surface of the test duct. For the circular test tube, the themocouples on each edge were equally spaced along the test section. In attempts to study the influences of duct wall geometry on heat transfer inside the rotating channel, the thermocouples for the square ribbed duct were set such that their axial locations corresponded precisely to the center and mid-pitch 
locations of the ribs. Two additional thermocouples were installed in the inlet and exit insulator bushes of both test sections in order to measure the flow entrance and exit temperatures for the subsequent evaluation of fluid temperature rise due to heat transfer.

\section{Method of Data Presentation and Reduction}

\section{1 Data presentation}

Due to rotation, the two physical manifestations responsible for significant modifications of the flow and temperature fields from those of the non-rotating situations, namely, the Coriolis and centripetal buoyancy effects, must be taken into account for accurately describing the heat transfer relationships of rotating duct flow. A study of the momentum conservation equations, with the fluid motion referred to a coordinate reference frame that rotates with the duct itself, suggests that fluid motion is governed parametrically by three dimensionless groups. These dimensionless groups are briefly described as follows and the full length of derivation is available in the works of Morris ${ }^{(1)}$ and Morris and Chang ${ }^{(14)}$.

The convective flow inertia that motivates fluid motion is characterized by the through-flow Reynolds number, $R e$, representing the ratio of inertial to viscous force effects. In a customary manner for forced convection, it is defined as

$$
R e=\frac{\rho W_{m} d}{\mu}
$$

where $W_{m}$ is the mean axial through-flow velocity, $d$ is the hydraulic diameter of test duct, $\rho$ is the density of fluid and $\mu$ is the coolant viscosity.

With the Coriolis force induced, the reciprocal of Rossby number (referred to as the inverse Rossby number), which represents the ratio of Coriolis to inertial force effect, is defined as

$$
\frac{1}{R o}=\frac{\Omega d}{W_{m}}
$$

where $\Omega$ is the angular velocity of the rotating duct. For stationary forced convection tests, the inverse Rossby number becomes zero, representing zero Coriolis effect.

The last dimensionless parameter, buoyancy number $(B u)$, represesting a measure of the influences of centripetal buoyancy, arises when the density variations due to heat transfer prevail over the flow domain, and is defined as

$$
B u=\frac{\beta\left(T_{w}-T_{f}\right)(\varepsilon+Z)}{R o^{2}},
$$

where $\beta$ is the coefficient of cubical expansion of the coolant, $\left(T_{w}-T_{f}\right)$ is a suitable representation of the temperature difference between the tube wall and the fluid, $\varepsilon$ is the dimensionless eccentricity measured from the flow entry plane with reference to the hydraulic diameter of duct, and $Z$ is the dimensionless axial location measured from the flow entrance and expressed in terms of equivalent hydraulic diameters of test duct. This buoyancy number involving centripetal acceleration is actually analogous to the Grashof or Rayleigh number that characterizes the gravitydriven buoyancy effect.

The result of convective heat transfer produced at any specified axial or angular location over the surfaces of a rotating duct is expressed in a customary manner by the local rotational Nusselt number, $\mathrm{Nu}$, and defined experimentally as

$$
N u=\frac{q d}{k\left(T_{w}-T_{f}\right)},
$$

where $q$ is the convective heat flux carried by flow, $k$ is the thermal conductivity of coolant, and $T_{w}, T_{f}$ represent the local wall temperature and the flow bulk temperature, respectively. Although the heat transfer of rotating flow is three-dimensional due to the Coriolis and buoyancy effects, we considered the heat transfer along the leading and trailing edges of each test duct in detail. " $\mathrm{L}$ " or " $\mathrm{T}$ " subscript was adopted to refer to these two specified locations in the tubewise direction.

In addition to the above dimensionless groups, to determine the heat transfer relationships, we need to specify the boundary conditions, such as the geometry of duct wall, and the heating and flow entry conditions. Thus the local heat transfer on the leading and trailing edges may be parametrically governed by an equation of the form

$$
\begin{aligned}
N u_{L, T}= & \Psi\left\{R e, \frac{1}{R o}, B u, \operatorname{Pr}, Z,\right. \text { boundary } \\
& \text { conditions }\},
\end{aligned}
$$

where $\Psi$ is an, as yet, unknown to be determined and $\mathrm{Pr}$ is the coolant Prandtl number. Our study was motivated by the need to incorporate the rotational effects in the design of internally cooled gas turbine rotor blades. A smooth-walled circular-sectioned tube and a rib-roughened square-sectioned duct, which were assumed to have the fundamental flow geometry with which to construct the internal airways of gas turbine rotor blade, were used to assess the rotational effects.

The parametric conditions at the flow entry plane involved several nominal Reynolds numbers in the range of 8000 to 35000 with four different rotational speeds, namely $0,1000,1500$ and $2000 \mathrm{rev} / \mathrm{min}$ which resulted in the variation of the inverse Rossby numbers from 0 to 0.54 . For each Reynolds or inverse Rossby number tested, five different heater power settings, that raised the wall temperature at mid-span location to $50^{\circ} \mathrm{C}, 75^{\circ} \mathrm{C}, 100^{\circ} \mathrm{C}, 125^{\circ} \mathrm{C}$ and $155^{\circ} \mathrm{C}$, 
systematically enhanced the buoyancy level. By increasing the density ratio, $\beta\left(T_{w}-T_{f}\right)$, from 0.05 to 0.4 and/or the inverse Rossby number from 0 to 0.54 , the buoyancy number was varied from 0 to 1.4 .

\section{2 Data reduction}

The energy released as heat by a portion of the electrical heating element is not entirely transferred to the fluid. Some of the generated heat is lost through the external insulation surrounding the test section and some is conducted through the test section wall. This amount of heat conduction loss to the surrounding material was eventually transferred into the surrounding atmosphere when rotational tests were performed. The remainder is transferred to the fluid as convective heat flux, $q$, as shown in Eq. (4).

Whenever there was a temperature difference between the rotating test rig and the atmosphere, the evaluation of heat conduction loss to the surrounding material was made via a number of heat loss precalibration runs at various rotational speeds in order to assess such heat loss characteristics. For each set of calibration runs, the thermal insulation material was filled within the test duct and the plenum chamber of the rotor arm. Heat that supplied to the test section will be entirely lost via conduction loss into the surrounding material. However, a corresponding steady-state duct wall temperature variation was eventually achieved and measured by the data acquisition system. It was assumed that all the dissipated heat was lost to the atmosphere and was related to the difference between mean wall and ambient temperatures. The mean wall temperature was calculated by integrating the axial wall temperature distributions and the plot of such heat loss against the temperature difference between mean wall and ambient values for each rotational speed was found to be linear. Thus, to estimate the external heat loss through material conduction at any given axial location of the test section, it was assumed that the local heat loss was proportional to the locally prevailing temperature difference between wall and ambient with the proportionality constant taken from the calibration plot. For the evaluation of Nusselt number, this amount of heat conduction loss to the surrounding material was deducted from the total heat supply based on the calibration results.

To estimate the net axial conductive heat along the duct wall at any axial location, the measured wall temperature distribution was numerically curve-fitted and a simple finite-difference representation of Fourier conduction law was used to estimate the net wall conduction.

The energy balance at which the thermocouple was embedded permitted the determination of axial variation of heat flux transferred into the coolant. Having determined the convective heat flux distribution by deducting the heat loss and conductive heat from the total heat supply, the bulk temperature of coolant, $T_{f}$, shown in Eq. (4) was calculated using an enthalpy balance starting with the known measured inlet coolant temperature and the known mass flow rate. A check of the calculated exit coolant bulk temperature against the measured exit temperature confirmed that the maximum discrepancy was of the order of $10 \%$, which was considered acceptable for this class of experiment.

The representative wall temperature, $T_{w}$, on the leading and trailing edges was estimated by a simple one-dimensional radial conduction correction of the measured value to a value corresponding to the inner surface of the test duct. Subsequently, all the dimensionless parameters in Eq. (5) along the leading and trailing surfaces were calculated with the fluid properties to be evaluated at the local bulk fluid temperature for convenience.

The uncertainty analysis of the data reduction equations suggested that most of the estimated errors in calculating Nusselt number were due to temperature measurement and the heat flux evaluation. As the fluid properties such as fluid viscosity and thermal conductivity were estimated using the temperaturedependent evaluation equations, errors in temperature measurements could result in uncertainties of Nusselt, Reynolds, Rossby and buoyancy numbers. Using the policy on reporting uncertainties in experimental measurements and the results of ASME Journal of Heat Transfer ${ }^{(15)}$, the estimated maximum errors for Nusselt, Reynolds, Rossby and buoyancy numbers were $11.05 \%, 5.2 \%, 4.8 \%$ and $5.5 \%$, respectively. Through the above analysis, as the percentage of error in temperature decreased with increasing temperature level, measurements made under maximum heat flux provided better accuracy. Similarly, the higher the Reynolds number tested, the better the results will be.

\section{Results and Discussion}

Prior to the rotational tests, a series of non-rotating heat transfer experiments for both smooth-walled and rib roughened ducts were undertaken for benchmark validation of test section construction, instrumentation and data processing methods, and for providing the heat transfer reference datum to which the rotational results could be compared. For both test sections with zero rotation, there was no noticeable difference in the local Nusselt numbers, $N u_{0}$, evaluated for the leading surface and its trailing counterpart. The axial Nusselt number variations of the smooth-walled 
tube for all the Reynolds numbers tested were consistent with data available in standard text books where the initially high Nusselt number value at the entry region of the tube decayed to a fully developed value and agreed with the well-known DittusBoelter ${ }^{(16)}$ correlation for developed turbulent flow. Since the range of coolant temperatures covered by the present experiments did not cause a significant change in the Prandtl number, the effect of Reynolds number on Nusselt number for the smooth-walled duct was well known to be taken into account via a 0.8 exponential relationship. Thus by plotting the axial heat transfer variations in terms of $N u_{0} / R e^{0.8}$ against the equivalent duct diameter downstream of the flow entry plane, all the local data collected from different Reynolds numbers should collapse onto a unique curve for the smooth-walled duct and this result is demonstrated in Fig. 5 in which the collapsed curve of axial heat transfer variation is seen to be consistent for the shape expected with a sharp-edged entry to a duct under a nominally uniform heat flux heating condition.

Also seen in Fig. 5 are the normalized axial Nusselt number variations along the rib-roughened square duct with which relevant available data from Han et al. ${ }^{(17)}$ and Johnson et al. ${ }^{(18)}$ are compared for validation. It is worthy to note that, despite the slight difference in the rib height for the rib geometry among the compared cases, the main difference in geometric feature is the length of the smooth-walled entrance in front of the first rib as indicated in Fig. 5. It was experimentally demonstrated that the length difference of the smooth-walled entrance may be the reason for the difference in axial heat transfer profiles in the flow developing region ${ }^{(7)}$. Good agreement

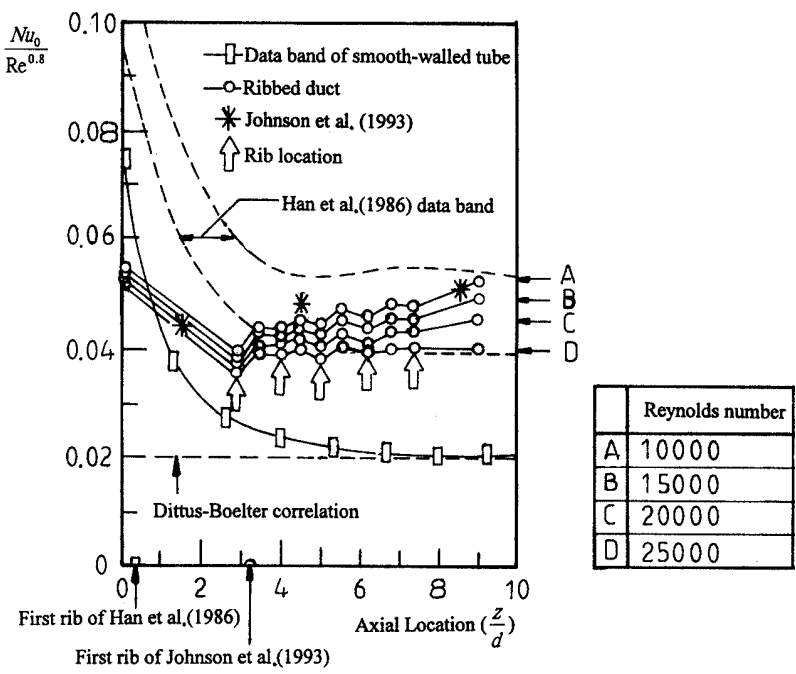

Fig. 5 Comparison of stationary scaled axial Nusselt number distributions with Dittus-Boelter correlation (1930), Han et al. (1986) and Johnson et al. (1993) among the compared data is observed in the range of $Z>4$. The data collapse for the rib-roughened ducts appears aa a systematically downward data spread when the Reynolds number is increased. It is interesting to note that the normalized Nusselt number, $N u_{0}$ / $R e^{0.8}$, seems to be Reynolds number-dependent with the higher ratios occurring at lower Reynolds numbers. This implies that the normal forced convection exponent of Reynolds number is different from the smooth-walled value of 0.8 and is actually axial location-dependent for this rib-roughened duct. This has also been reported by Morris and Salemi ${ }^{(6)}$ for a circular tube fitted with full circumferential ribs.

Noting that the Prandtl number remains relatively constant with these tests, the variation of Reynolds number exponent was examined by assuming that the local Nusselt number could be correlated by an equation having the structure given in Eq. (6) at the rib and mid-rib locations.

$$
N u_{0}=A(Z) \times R e^{n(Z)}
$$

in which $A$ and $n$ are axial location-dependent coefficients and their variations along the axial test duct illustrated in Fig. 6.

In Fig. 6, the exponent, $n$, of Reynolds number tends to decrease from an initial level of 0.79 toward 0.69 as the rib number increases. In Taslim and Spring(13) for which the Nusselt number was shown to be proportional to $R e^{0.6}$ in the developed flow region for a square duct fitted with transverse ribs having rib-height to pitch ratio, $P / e$, of 10 and $e / d$ of 0.1 . Thus the exponent, $n$, of 0.69 at the fifth rib in the present study indicates that the flow inside the rib

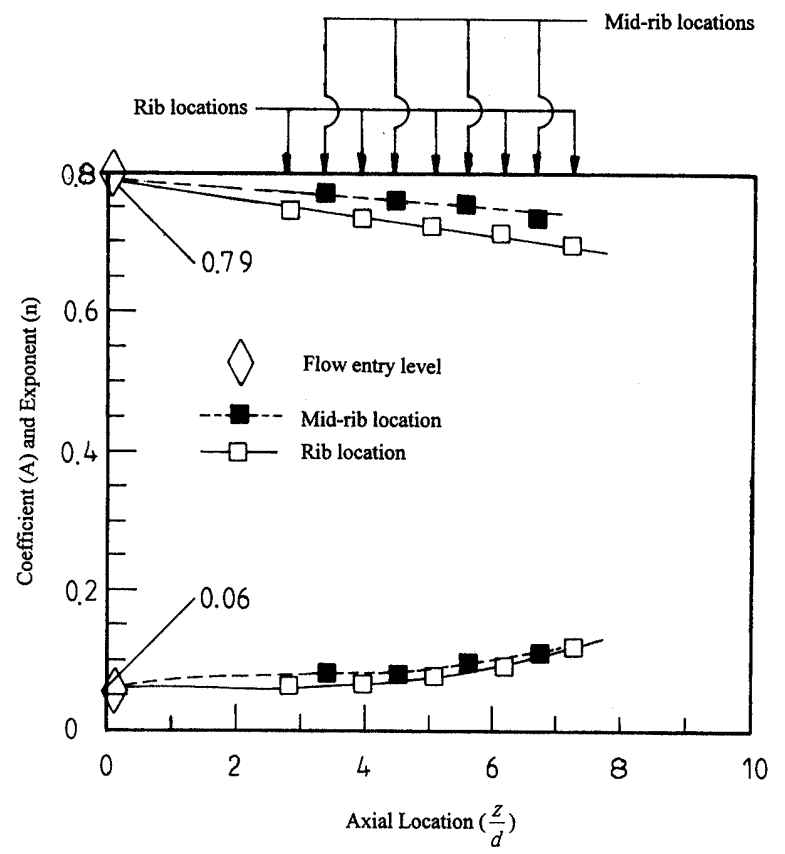

Fig. 6 Effect of ribs on stationary Nusselt number/ Reynolds number correlation For ribbed flow 
area is probably not yet fully developed. What is interesting is that the exponent, $n$, of 0.79 at the sharp flow entrance approaches the well-established 0.8 value for the smooth-walled duct flow and such influences of forced convective inertia on heat transfer tend to become weak in the downstream direction when flow traverses the ribs. This is indicated by the decay of exponent, $n$, shown in Fig. 6 . Accompanying the decay of exponent, $n$, along the ribbed duct is the corresponding increase in coefficient $A$, which could be seen as an indication of the heat transfer enhancement by the transverse ribs. When the exponents, $n$ approach to a constant value of about 0.6 where the "periodic" fully developed flow is established between rib cells, the most significant rib effects on heat transfer are observed. If the same approach is applied to the smooth-walled duct flow using Eq. (6), the data shown in Fig. 6 for the smooth-walled duct suggest that the exponent $n$ could be taken as 0.8 for both developing and developed flows.

With the effects of forced convective inertia on the stationary heat transfer quantified by the exponent, $n$, in Eq. ( 6 ), we investigate if the effects of Reynolds number could be isolated from the rotational effects if Eq. ( 5 ) is normalized by Eq. (6) The rotational effects on heat transfer may take the form

$$
\begin{aligned}
& \frac{N u_{L, T}}{N u_{0}}= \\
& \phi \frac{\left\{R e, \frac{1}{R o}, B u, \operatorname{Pr}, Z, \text { boundary conditions }\right\}}{A R e^{n(Z)}} .
\end{aligned}
$$

In order for the overall effect of Reynolds number on the right-hand side of Eq. (7) to vanish or be reduced to a small value, the mathematical structure of Reynolds number in the numerator of Eq. (7) should be, at least, close to $R e^{n(Z)}$ shown in the denominator of Eq. ( 7 ). If the above hypothesis is true, then the rotational data in terms of $\frac{N u_{L, T}}{R e^{n(Z)}}$ will be independent of Reynolds number and therefore the experimental correlation for this mode of rotating flow can be greatly simplified. This hypothesis has been experimentally investigated by conducting heat transfer tests with fixed values of the inverse Rossby number but with different combinations of rotational speed and Reynolds number. For the smooth-walled round duct, Morris et al. ${ }^{(18)}$, and Morris and Salemi ${ }^{(6)}$ have proposed a hypothesis that the effect of Reynolds number on rotational heat transfer could be fully accounted for by the 0.8 exponent appropriate for the forced convection. This hypothesis for smooth-walled
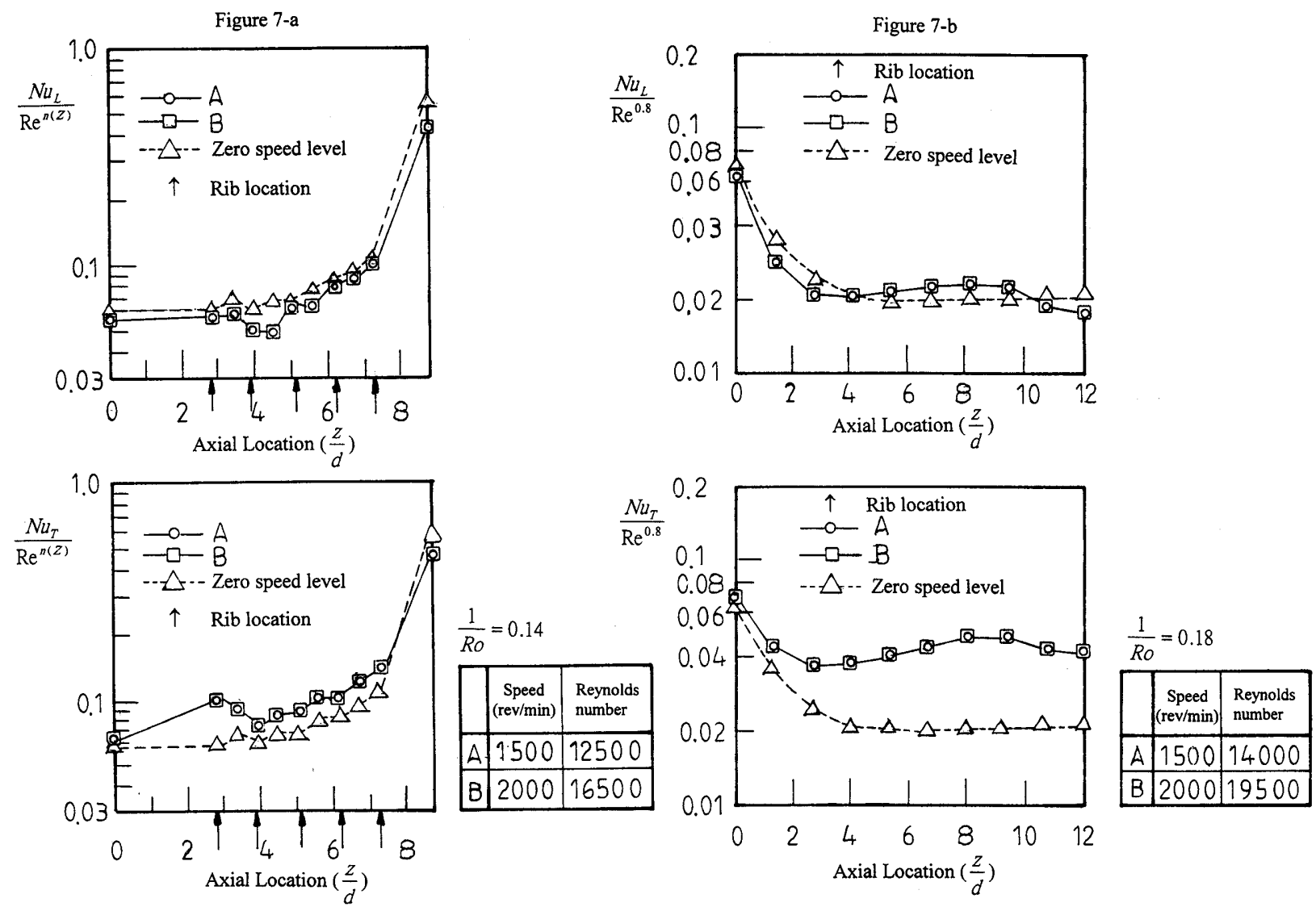

Fig. 7 Normalized axial Nusselt number distributions at fixed inverse Rossby number with different Reynolds numbers 
duct has been experimentally demonstrated by Morris and Chang ${ }^{(14)}$. However, for the rib-roughened square duct, for which the exponent, $n$, may be no longer a constant if the flow is not yet fully developed, the effect of Reynolds number could not be accounted for by the 0.8 exponent in accordance with the previous reports. Instead of using $R e^{0.8}$ to account for the Reynolds number effect on heat transfer inside a rotating ribbed duct, the rotational heat transfer results with fixed values of the inverse Rossby number but different rotational speeds and Reynolds numbers for the leading and trailing edges are plotted in terms of $\frac{N u_{L, T}}{R e^{n(Z)}}$ against the non-dimensional axial location. Typical results for ribbed duct are shown in Fig. 7 (a), and for a comparison between ribbed and smooth walled test channels, the rotational smoothwalled heat transfer values in terms of $\frac{N u_{L, T}}{R e^{0.8}}$ are presented Fig. 7(b). It should be noted that the experimental data selected to construct Figs. 7(a) and $7(b)$ were chosen such that they had approximately the same average value of $\beta\left(T_{w}-T_{f}\right)$ in order to keep the buoyancy effect constant when these data were generated. In both figures, the equivalent heat transfer data with zero rotational speed are also included for the assessment of the general rotational effect on heat transfer.

As shown in Figs. $7(\mathrm{a})$ and $7(\mathrm{~b})$, the strong tendency for data at fixed inverse Rossby number and different Reynolds numbers to collapse onto a single curve is observed at the leading and trailing surfaces for both ribbed and smooth-walled ducts. This suggests that the Reynolds number effect on heat transfer inside a rotating duct could be accounted for via the normal stationary duct forced convection relationship of $R e^{n(Z)}$. On the leading edges of both test sections, the heat transfer values can fall below those of the stationary duct levels. In contrast, considerable heat transfer increase relative to that of the non-rotating situation takes place on the trailing edge, which demonstrates the formation of Coriolis secondary flow inside the rotating ribbed and smooth-walled ducts.

In an attempt to compare the variable rotational effects on heat transfer inside smooth-walled and ribbed ducts, two sets of experiments were conducted with the averaged value of the term $\beta\left(T_{w}-T_{f}\right)$ maintained at approximately 0.15 . For this series of tests, experiments were undertaken with inverse Rossby numbers controlled at $0.1,0.2,0.3,0.4$ and 0.5 . The rotational Nusselt number values, $N u_{L, T}$, measured from these sets of experiments were subsequently normalized by the equivalent stationary Nusselt number values, $N u_{0}$, in order to show the effect of rotation on heat transfer. Figures $8(\mathrm{a})$ and $8(\mathrm{~b})$ show the axial distributions of such Nusselt number ratios on the leading and trailing surfaces, respectively. For each individual plot of Figs. $8(\mathrm{a})$ and $8(\mathrm{~b})$, two sets of heat transfer data with the same inverse Rossby number measured from the smooth-walled and ribbed ducts are compared.

The flow entrances for the circular smoothwalled and square ribbed ducts were both sharp-edged with sudden contraction. For this particular geometry, the values of Nusselt number ratio, $\frac{N u_{L, T}}{N u_{0}}$, at the immediate flow entrance shown in Figs. 8(a) and 8 (b) tend to approach unity for both test ducts. Thus, the dominant flow physics at this axial spot may be the redevelopment of flow boundary layers rather than the rotation-related flow phenomena. Further downstream, the values of Nusselt number ratio, $\frac{N u_{L, T}}{N u_{0}}$, gradually deviate from unity, which indicates the "growing" influence of rotational effects. On the leading surface, the values of Nusselt number ratio shown in Fig. 8(a) are less than unity for both smooth-walled and ribbed test ducts when the values of inverse Rossby number are relatively low. For the circular smooth-walled tube, the rotational Nusselt number value, $N u_{L, T}$, can be reduced to about $75 \%$ of the equivalent stationary tube value at an axial location of $0.18 \frac{Z}{L}$ when the inverse Rossby number is controlled at 0.1 . For the ribbed duct, the most significant heat transfer impediment that causes the rotational Nusselt number to decrease to about $65 \%$ of the stationary value is found at an axial position of $0.6 \frac{Z}{L}$ with the inverse Rossby number valued at $0.2 \sim$ 0.3. This Nusselt number reduction is particularly important for the design of turbine rotor blades because this effect must be included in the analysis of internal cooling performance. When the value of inverse Rossby number reached 0.5 , the values of Nusselt number ratio for both smooth-walled and ribbed ducts are all above unity, indicating heat transfer enhancement due to rotation. This result agrees with those reported by Wagner et al. ${ }^{(1)}$ in which heat transfer enhancement on the leading surface for radial outward rotating flow can result if the inverse Rossby number and buoyancy level are relatively high. However, the difference in the axial distributions of Nusselt number ratios between the smooth-walled tube and the ribbed duct at each inverse Rossby number depicted in the plots of Fig. 8( a ) is evident. The variable rotational effect between smooth-walled and ribbed ducts is thus demonstrated and in general, 
considerable heat transfer impediment on the leading surface was found for the square ribbed duct.

On the trailing surfaces of both rotating ducts, all the data plotted in terms of Nusselt number ratio as shown in Fig. 8(b) are greater than unity after the flow passed the immediate flow entrance. For the smooth-walled tube, a strong tendency for this rotational effect to be increased in the downstream direction is clearly shown, especially when the value of inverse Rossby number is relatively high. However, perhaps due to the developing nature of ribbed duct flow as illustrated previously and/or the interference of rib-associated flow phenomena on the rotational effect, the degree of heat transfer increase taking place within the rib area of the square ribbed duct does not show strong dependence on the axial location. Nevertheless, when the value of inverse Rossby number increases from 0.1 to 0.5 , systematic heat transfer increments for both smooth-walled and
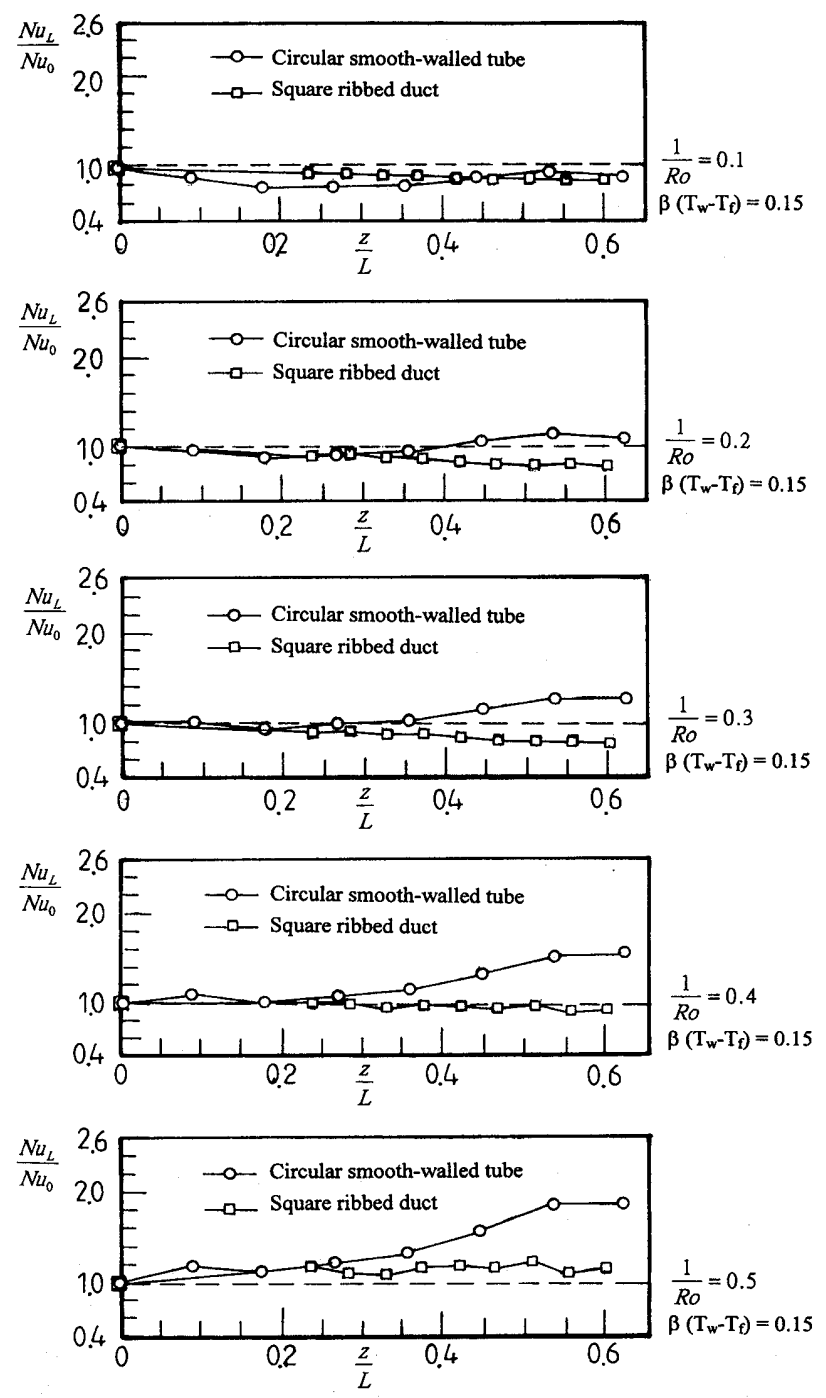

Fig. 8( a ) Variable rotational effects on leading surface heat transfer between circular smooth-walled and square ribbed test ducts ribbed ducted flows are observed. Upon comparison of the data between square ribbed duct and circular smooth-walled duct at equivalent rotating conditions, the heat transfer enhancement in the square ribbed duct is found to be rather moderate, which demonstrates the influences of duct wall geometry on the rotational effect.

Because the rotational effect in the ribbed duct was considerably suppressed as described previously, the possible beneficial rotational effect on heat transfer under certain rotating conditions was also reduced for ribbed duct flow as shown in Fig. 8(b). Therefore, even if the stationary heat transfer level of ribbed duct flow was considerably superior to that of the smooth-walled test section as illustrated in Fig. 5, a comparison of the absolute heat transfer levels
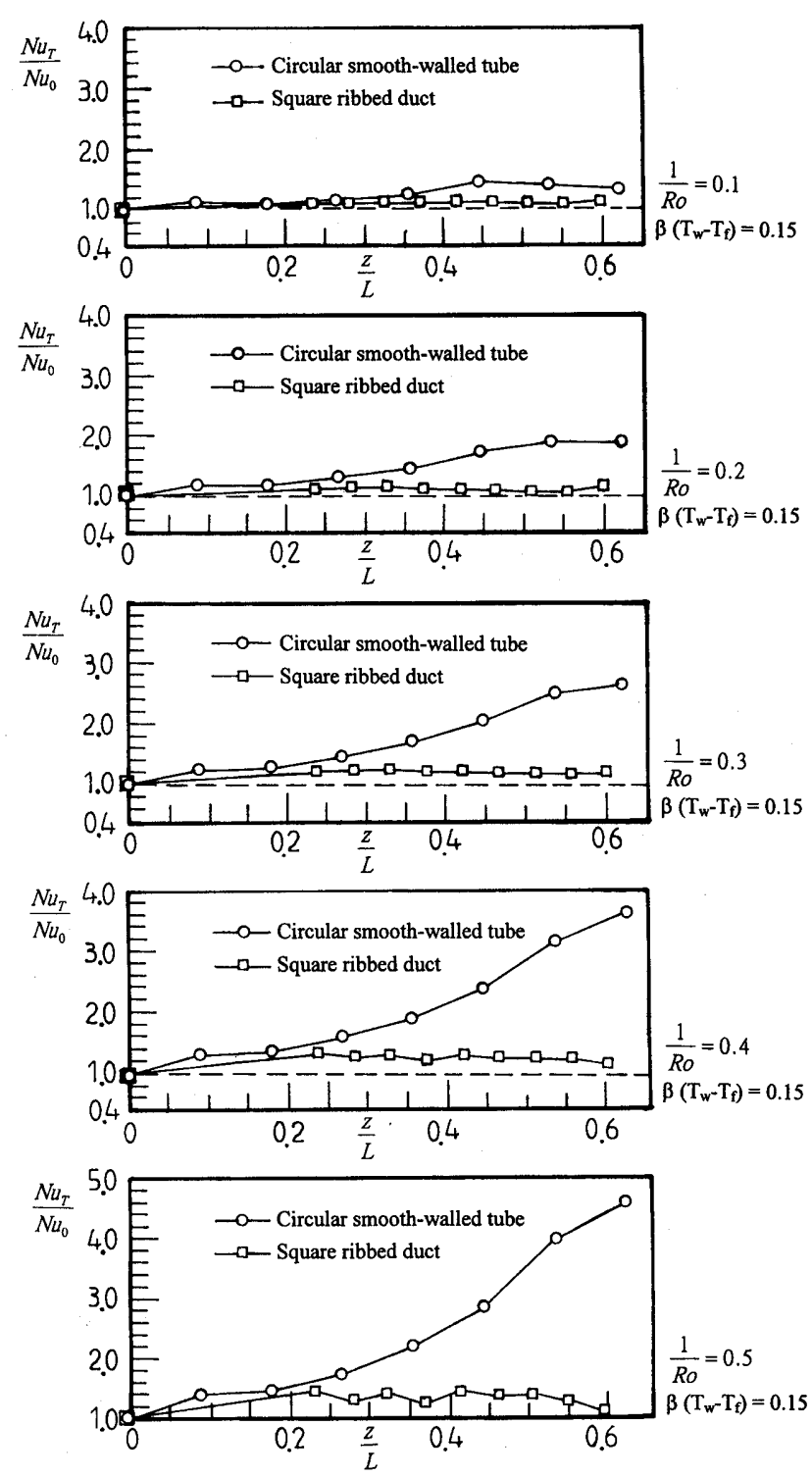

Fig. 8 (b) Variable rotational effects on trailing surface heat transfer between circular smooth-walled and square ribbed test ducts 
between the smooth-walled and ribbed test sections at higher rotation rates could vary from the results shown by the stationary comparison due to the different rotational effects. To illustrate, the rotational Nusselt number data for both smoothwalled and ribbed ducts were normalized by the same heat transfer reference of the Dittus-Boelter correlation $^{(16)}, N u_{\infty}$, in order to compare the Nusselt number levels in an absolute sense. Figures $9(\mathrm{a})$ and 9 ( b ) compare the variations of absolute heat transfer levels in terms of $\frac{N u_{L, T}}{N u_{\infty}}$ with the buoyancy number, $B u$, between the smooth-walled and ribbed test sections for the leading and trailing surfaces, respectively. As shown in all the plots, the zero-speed heat transfer data of the smooth-walled test duct are considerably lower than those of ribbed duct. In general, an overall tendency for the heat transfer levels to be increased with an increase in buoyancy number for both smooth-walled and ribbed ducts is
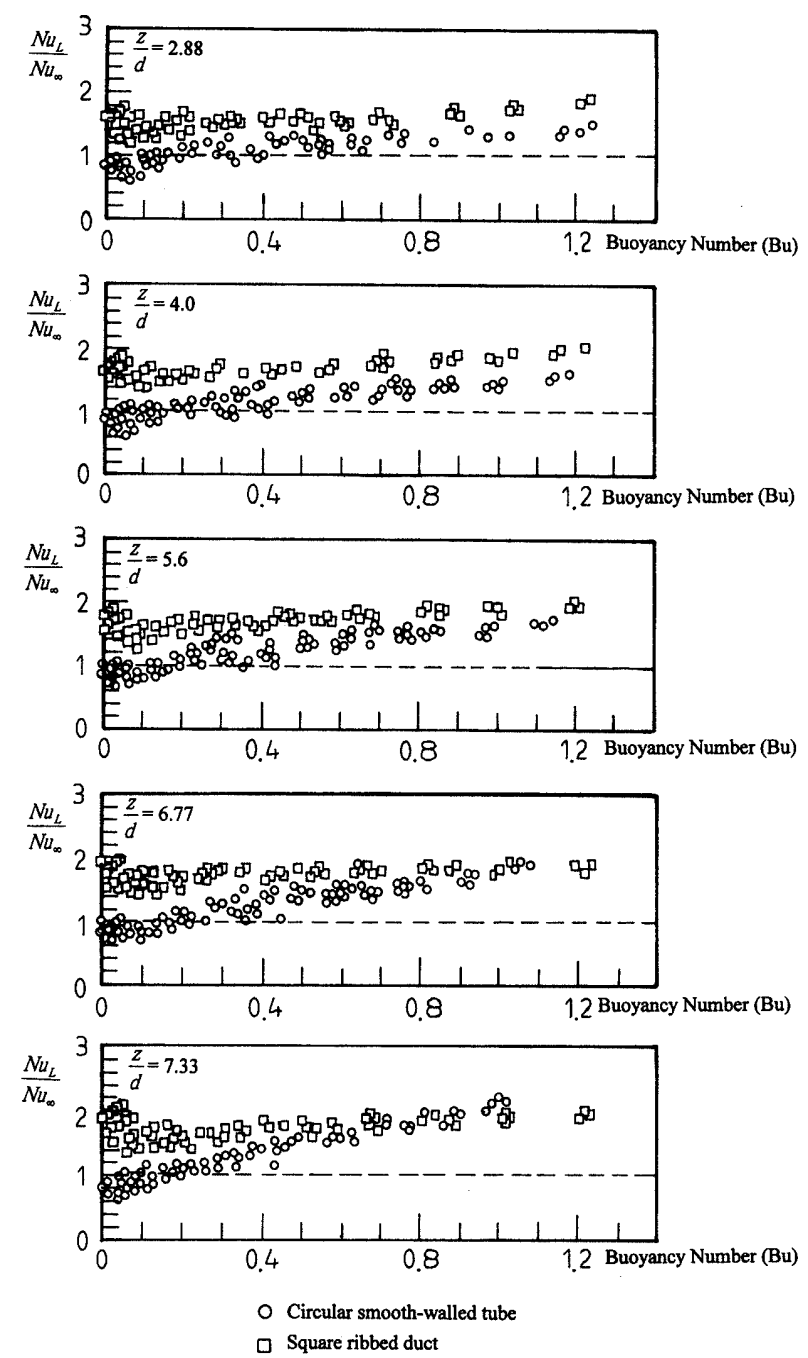

Fig. 9(a) Comparison of leading surface heat transfer results between circular smooth-walled and square ribbed test ducts shown in the plots in Figs. $9(\mathrm{a})$ and $9(\mathrm{~b})$. In this respect, the steeper gradient of the heat transfer increase rate for the smooth-walled test tube may indicate a more significant buoyancy effect inside the smooth-walled test duct, and this particular result indicates an improvement of heat transfer inside the smooth-walled duct over those the ribbed duct in further downstream locations when the buoyancy numbers are relatively high. However a comparison of Figs. 9( a ) with $9(\mathrm{~b})$ indicates differences in heat transfer values between leading and trailing surfaces at an axial location with fixed buoyancy number, which confirms the presence of peripheral heat transfer variations inside the rotating ducts. This peripheral heat transfer variation is created by rotationinduced secondary flows and generally, such heat transfer difference between leading and trailing surfaces is greater for the smooth-walled test duct than for the ribbed duct, which suggests less peripheral heat transfer variation for rotating ribbed duct flow.
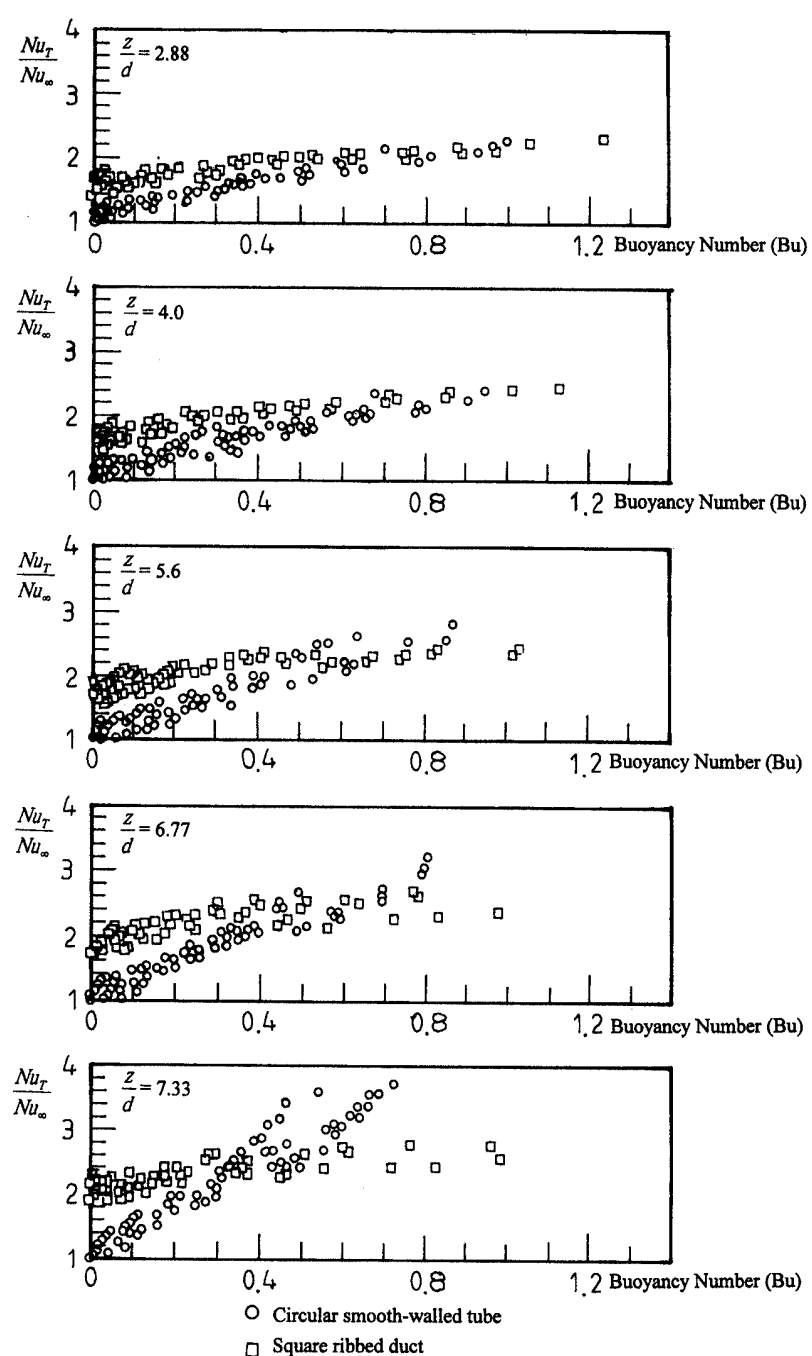

Fig. 9(b) Comparison of trailing surface heat transfer results between circular smooth-walled and square ribbed test ducts 
Therefore, the selection of either smooth-walled or transverse rib-roughened coolant channel for gas turbine rotor blades must be done while considering the variable rotational effects in order to achieve an optimum design of the internal cooling system.

\section{Conclusions}

We illustrated differences in variable rotational effects on heat transfer between the circular smoothwalled duct and the square duct fitted with transverse ribs, for application to the design of cooled gas turbine rotor blades. Various rotational effects on heat transfer between these two test sections were the results of differences in the shape of cross section and wall surfaces. Several salient points which have been demonstrated are summarized as follows.

1. The presence of strong rotation-induced secondary flows was found for both test sections with an attendant relative increase in local heat transfer on the trailing surface of the duct. In all cases, the trailing edge heat transfer was greater than that expected from stationary forced convection. On the leading surface, heat transfer was significantly lower than the pure forced convection level but at high rotation rates, this impediment was reduced and recovered so that the local heat transfer could be higher than that of the equivalent stationary convection case. However, in all instances heat transfer on the trailing edge was better than that on the leading edge.

2. In qualitative terms, the effects of rotation with respect to either the inverse Rossby or buoyancy number for smooth-walled and ribbed test sections were similar. Even with the agitated flow field caused by the ribs, considerable rotational effects occurred in a manner similar to that described for the circular smooth-walled duct. However, under equivalent rotating conditions, the heat transfer impediment on the leading surface was more severe for the ribbed duct flow than for the smooth-walled duct flow. Compared with the results of the smooth-walled test duct, the rotational effect on the trailing surface of the ribbed duct was significantly reduced. Less degree of peripheral heat transfer variation was thus observed in the ribbed test duct.

3. The effect of forced convection might be isolated from those of rotation related flow phenomena by scaling the rotational Nusselt number with a Reynolds number raised to the power $n(Z)$. The exponential function, $n(Z)$, remained constant at 0.8 for the smooth-walled test tube, whereas, for the square ribbed duct, the Reynolds number exponent was found to be dependent on the rib cell location along the duct. As the Reynolds number effects could be functionally related with the rotation forces using $R e^{n(Z)}$, the derivation of heat transfer correlation for this mode of rotating flow could be considerably simplified.

\section{Acknowledgement}

This research project was made possible by funding and research facilities from the Defense Research Agency and Rolls Royce Plc. UK., and the award of ORS.

\section{References}

(1) Morris, W.D., Heat Transfer in Rotating Coolant Channels, (1981), Research Studies Press, John Wiley and Sons.

(2) Rothe, P.H. and Johnston, J.P., Free Shear Layer Behaviour in Rotating Systems, ASME Journal of Fluid Engineering, Vol. 101 (1979), p. 117-120.

(3) Mori, Y., Fukada, T. and Nakayama, W., Convective Heat Transfer in a Rotating Radial Circular Pipe, ( $2^{\text {nd }}$ Report, Turbulent Region), Int. J. Heat and Mass Transfer, Vol. 14 (1971), p. 18071824.

(4) Morris, W.D. and Ayhan, T., Observations on the Influence of Rotation on Heat Transfer in the Coolant Channels of Gas Turbine Rotor Blades, Proc. Inst. Mech. Eng., Vol. 193, No. 21 (1979), p. 303.

( 5 ) Medwell, J.O., Morris, W.D., Xia, J.Y. and Taylor, C., An Investigation of Convective Heat Transfer in a Rotating Coolant Channel, ASME Gas Turbine and Aeroengine Congress and Exposition, June 11-14, Brusselt, Belgium, 1990.

(6) Morris, W.D. and Salemi, R., Attempt to Experimentally Uncouple the Effect of Coriolis and Buoyancy Forces on Heat Transfer in Smooth Circular Tubes which Rotates in the Orthogonal Mode, ASME Journal of Turbomachinery, Vol. 114 (1992), p. 858-864.

(7) Chang, S.W., An Experimental Study of Heat Transfer in the Cooling Passages of Gas Turbine Rotor Blades, Doctoral dissertation, Department of Mechanical Engineering, University of Wales, Swansea, UK, (1995).

( 8 ) Han, J.C. and Zhang, Y.M., Effect of Uneven Wall Temperature on Local Heat Transfer in a Rotating Square Channel with Smooth Walls and Radial Outward Flow, ASME Journal of Heat Transfer, Vol. 114 (1992), p. 850-858.

(9) Han, J.C., Zhang, Y.M. and Kalkuehler Kathrin, Uneven Wall Temperature Effect on Local Heat Transfer in a Rotating Two-pass Square Channel with Smooth Walls, ASME Journal of Heat Transfer, Vol. 115 (1993), p. 912-920.

(10) Johnson, B.V., Wagner, J.H., Steuber, G.D. and Yeh, F.C., Heat Transfer in Rotating Serpentine Passages with Trips Skewed to the Flow, ASME Journal of Turbomachinery, Vol.116 (1994), p. 113-123. 
(11) Wagner, J.H., Johnson, B.V., Graziani, R.A. and Yeh, F. C., Heat Transfer in Rotating Serpestine Passages with Trips Normal to the Flow, ASME Journal of Turbomachinery, Vol.114 (1992), p. 847-858.

(12) Taslim, M.E., Bondi, L.A. and Kercher, D.M., An Experimental Investigation of Heat Transfer in an Orthogonally Rotating Channel Roughened with 45 Degree Criss-Cross Ribs on Two Opposite Walls, ASME Journal of Tubomachinery, Vol. 113 (1991), p. 346-353.

(13) Taslim, M.E., Rahman, A. and Spring, S.D., An Experimental Investigation of Heat Transfer Coefficient in a Spanwise Rotating Channel with Two Opposite Rib-Roughened Walls, ASME 89GT-150, Toronto, Ontario, Canada, (1989).

(14) Morris, W.D. and Chang, S.W., An Experimental Study of Heat Transfer in a Simulated Turbine Blade Cooling Passage, International Journal of Heat and Mass Transfer, Vol. 40, No. 15 (1997) p. 3703-3716.
(15) Editorial Board of ASME Journal of Heat Transfer, Journal of Heat Transfer Policy on Reporting Uncertainties in Experimental Measurements and Results, ASME Journal of Heat Transfer, Vol. 115 (1993), p. 5-6.

(16) Dittus, F.W. and Boelter, L.M.K., Calif. Pubs., Engng, Vol. 2 (1930), p. 443.

(17) Han, J. C., Park, J. S. and Lei, C. K., Heat Transfer and Pressure Drop in Blade Cooling Channels with Turbulence Promoters, NACA Contract Report 3837, (1984).

(18) Johnson, B.V., Wagner, J.H. and Steuber, G.D., Effects of Rotation on Coolant Passage Heat Transfer, NASA Contract Report 4396, Vol. II (1993).

(19) Morris, W.D., Harasgama, S.P. and Salemi, R., Measurements of Turbulent Heat Transfer on the Leading and Trailing Surfaces of a Square Duct Rotating in the Orthogonal-Mode, ASME Gas Turbine and Aeroengine Congress and Exposition, Amsterdam, Netherlands, 1988. 